Journal: Industrial \& Engineering Chemistry Research

Manuscript ID: ie-2019-06581v

Manuscript Title: Stability Analysis of Gas Solids Distribution through Nonidentical Parallel Paths

Author(s): Zhang, Chenxi; Xu, Qi; Bourane, Abdennour; Ghrami, Musaed; Abba, Ibrahim Wei, Fei.

\title{
Stability Analysis of Gas Solids Distribution through Non- identical Parallel Paths
}

Chenxi Zhang*1, Qi Xu², Abdennour Bourane², Musaed Ghrami², Ibrahim Abba ${ }^{2}$, Fei Wei*1.

First author \& Corresponding author:

Dr. Chenxi Zhang E-mail: cxzhang@mail.tsinghua.edu.cn

Professor Fei Wei E-mail: wf-dce@mail.tsinghua.edu.cn

( ${ }^{1}$ Department of Chemical Engineering, Beijing Key Laboratory of Green Reaction Engineering and Technology, Tsinghua University, Beijing 100084, China.

${ }^{2}$ Research \& Development Center, Saudi Aramco, Dhahran 31311, Saudi Arabia) 


\section{Supplementary Materials}

\section{Details of pressure drop calculation in the present study}

\section{Dense Fluidization}

In the regenerator, air is input from the base via distributor and solids from two strippers (Path A and B) enter at the upper section. At the top of regenerator, there is a filter to separate the solids. Three differential pressure sensors (one is above the distributor $10 \mathrm{~mm}$, one is into the dense solids bed above distributor $50 \mathrm{~cm}$ and the other is at the dilute section below the filter $10 \mathrm{~mm}$ ) are used to measure the total pressure drop $\left(\Delta P_{R}\right)$ and average density $\left(\rho_{\text {ave }}\right)$ in the regenerator. The relationship between $\Delta P_{R}$ and $\rho_{\text {ave }}$ can be expressed as

$$
\Delta P_{R}=\rho_{\text {ave }} g H
$$

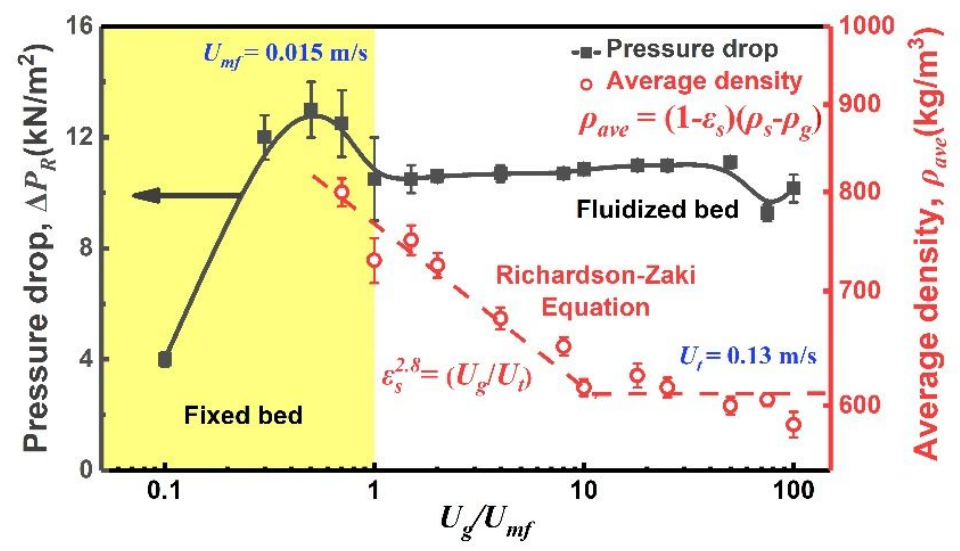

Figure S-1. The effect of superficial gas velocity $\left(U_{g}\right)$ on pressure drop $\left(\Delta P_{R}\right)$ and average density $\left(\rho_{\text {ave }}\right)$ in regenerator.

Figure S-1 illustrates the role of fluidization quality $\left(U_{g} / U_{m f}\right)$ on pressure drop $\left(\Delta P_{R}\right)$ and average density $\left(\rho_{\text {ave }}\right)$ in regenerator. According to the Grace's equation ${ }^{1}$, the minimal fluidization velocity $\left(U_{m f}\right)$ is $0.013 \mathrm{~m} / \mathrm{s}$ and our experimental result is 0.015 $\mathrm{m} / \mathrm{s}$.

$$
\operatorname{Re}_{m f}=\frac{U_{m f} d_{p} \rho_{g}}{\mu_{g}}=\sqrt{27.2^{2}+0.0408 A r}-27.2
$$

In order to gain smooth fluidization, superficial gas velocity in regenerator, two hoppers and two strippers is ensured as 10 times of minimal fluidization velocity $\left(U_{m f}\right)$, i.e. $U_{g} / U_{m f}=10$. In addition, the void fraction of solids bed $\left(\varepsilon_{s}\right)$ can be well described by 
Richardson-Zaki equation ${ }^{2}$ :

$$
\varepsilon_{s}^{n}=\frac{U_{g}}{U_{t}}
$$

where $U_{t}$ is the terminal fall velocity of particle and the expansion parameter $n$ depends on the free falling particle Reynolds number $\left(\mathrm{Re}_{t}\right)$, in the range between 4.8 (viscous regime) and 2.4 (turbulent regime). In the present study, $U_{t}=0.13 \mathrm{~m} / \mathrm{s}$ and $n=2.8$.

According to $\mathrm{Eq}(\mathrm{S} 1)-(\mathrm{S} 3)$, when the superficial gas velocity $\left(U_{g}\right)$, total solids loading $\left(m_{S T}\right)$ and geometrical parameters of regenerator are given, the pressure drop for dense fluidization in regenerator is only determined by the height of solids bed, which is a function of solids circulation rate. Similarly, the total pressure drop in both hoppers and strippers (Path A and B) has the first order relationship with solids circulation rate $\left(C_{T i}\right)$, which can be expressed as:

$$
\begin{gathered}
\Delta P_{H i}=\frac{k_{H} g}{A_{H i}} C_{T i} \quad(i=A, B) \\
\Delta P_{S i}=\frac{k_{S} g}{A_{S i}} C_{T i} \quad(i=A, B)
\end{gathered}
$$

where $k_{H}$ and $k_{S}$ is the constants of hopper and stripper, respectively. In the present study, $k_{H}=0.16 \times 10^{-3} h$ and $k_{S}=0.07 \times 10^{-3} h$.

\section{Solids Circulation rate}

Figure S-2(a) illustrates the positive relationship between solids circulation rate $\left(C_{T i}\right)$ and outlet temperature of cooling jacket $\left(t_{2}\right)$ in Path A and B, respectively. The fitting line is calculated from Eq. S1, indicating it is a reliable method to detect the solids circulation rate with cooling jacket. The difference between those two fitting lines results from the different geometrical parameter of two catalyst transport lines as listed in Table 1.

The slide valve at the bottom of transport line plays an independent role in controlling solids circulation rate in Path A and B. Thus, the effect of both valve opening $\left(\Phi_{i}\right)$ and solids circulation rate $\left(C_{T i}\right)$ on pressure drop across slide valve $\left(\Delta P_{V i}\right)$ should be investigated carefully. Figure S-2(b) and (c) indicates the contribution from 
solids circulation rate on pressure drop across slide valve with different opening fraction in Path A and B, respectively. Since solids across the bifurcation of regenerator and slide valve is dense flow, the pressure drop $\left(\Delta P_{V i}\right)$ mainly results from frictional dissipation across slide valve. The characteristics of frictional dissipation, an increase in solids concentration enhances energy dissipation during the initial stage while the further positive role will be decreased, can be well expressed as the following equation ${ }^{3}$, 4.

$$
\Delta P_{V i}=C d_{V i} \sqrt{C_{T i} g} \quad(i=A, B)
$$

where $C d_{V i}$ is the superficial drag coefficient of slide valve.

(a)

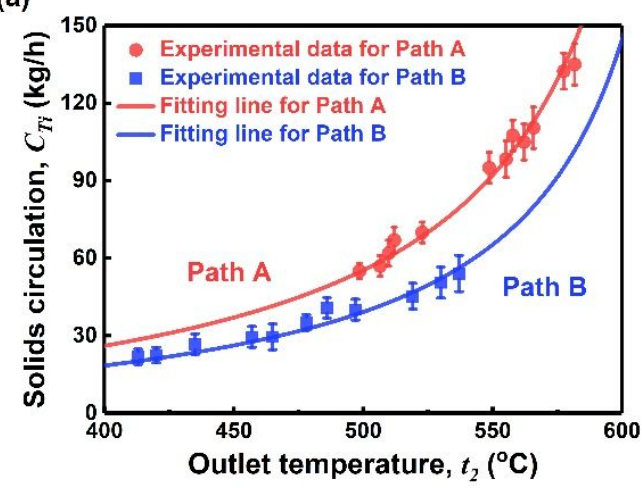

(c)

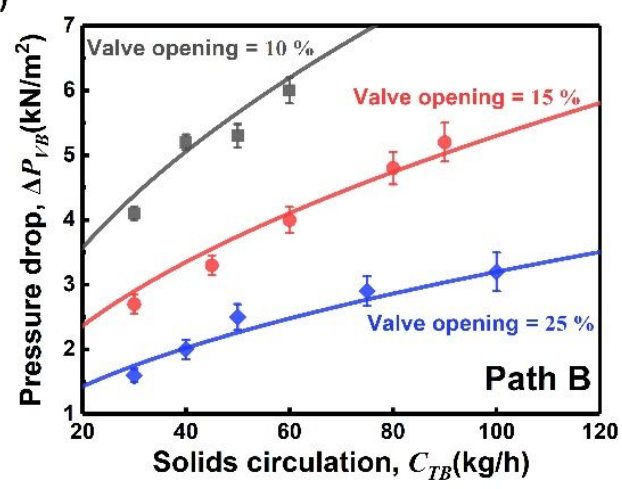

(b)

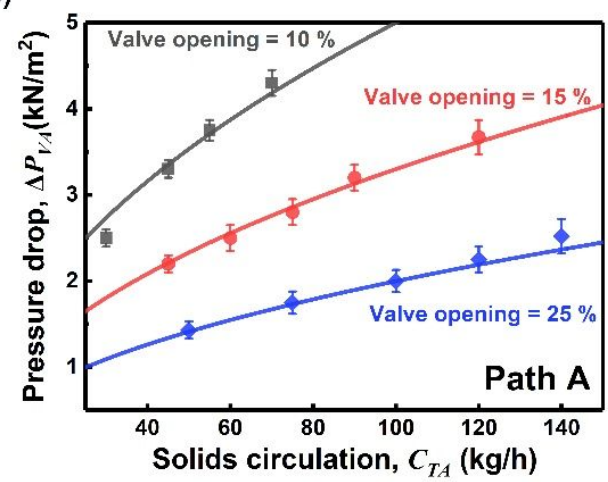

(d)

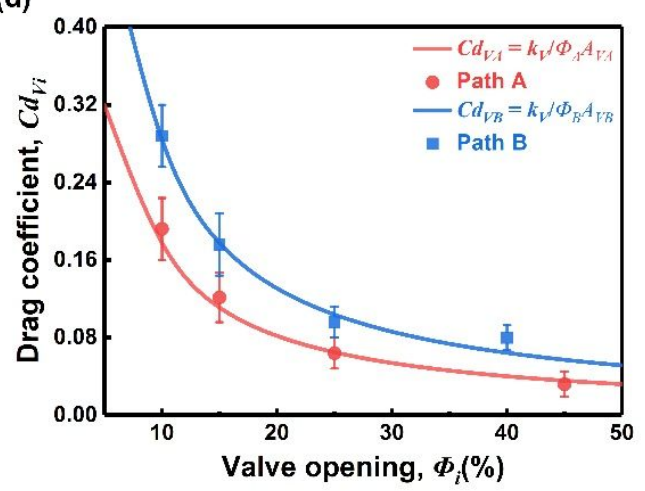

Figure S-2. (a) The relationship between solids circulation rate $\left(C_{T_{i}}\right)$ and outlet temperature of cooling jacket $\left(t_{2}\right)$ for Path $A$ and B; (b) The effect of solids circulation rate $\left(C_{T A}\right)$ on pressure drop across slide valve $\left(\Delta P_{V A}\right)$ with different valve opening $\left(\Phi_{A}\right)$ in Path $A$; (c) The effect of solids circulation rate $\left(C_{T B}\right)$ on pressure drop across slide valve $\left(\Delta P_{V B}\right)$ with different valve opening $\left(\Phi_{B}\right)$ in Path B; (d) The relationship between valve opening $\left(\Phi_{i}\right)$ and superficial drag coefficient of slide valve $\left(C d_{V i}\right)$ for Path $A$ and $B$.

The negative effect of valve opening $\left(\Phi_{i}\right)$ on $C d_{V i}$, as shown in Figure S-2(d), can be well described: 


$$
C d_{V i}=\frac{k_{V}}{\Phi_{i} A_{V i}} \quad(i=A, B)
$$

where the correlation constant $k_{V}=1.63 \times 10^{-3}(N \cdot h)^{-1 / 2}$ in the present study. Therefore, the relationship between both geometrical parameter (valve opening, $\Phi_{i}$ ) and operational condition (solids circulation rate, $C_{T i}$ ) and the pressure drop across slide valve $\left(\Delta P_{V i}\right)$ can be well expressed as the following equation:

$$
\Delta P_{V i}=\frac{k_{V}}{\Phi_{i} A_{V i}} \sqrt{C_{T i} g} \quad(i=A, B)
$$

\section{Transport lines and Downers}

Comparing with dense solids flow across slide valve, the contribution from dilute solids phase to pressure drop through transport lines (before hoppers and after strippers) comes from two parts: (i) an increase in average density; (ii) a kinetic energy dissipation of solids phase. Since the superficial gas velocity is constant, the contribution from average density is significant as shown in Figure S-3(a). Thus, it can be written as the following equation:

$$
\Delta P_{t i}=\frac{k_{t} g}{A_{t i}} C_{T i} \quad(i=A, B)
$$

(a)

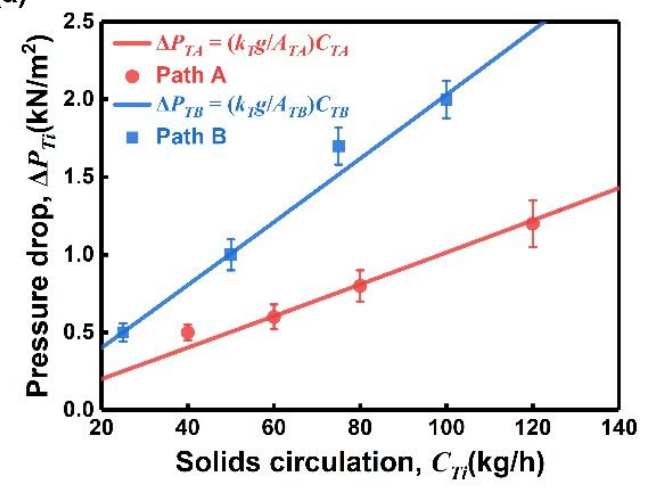

(b)

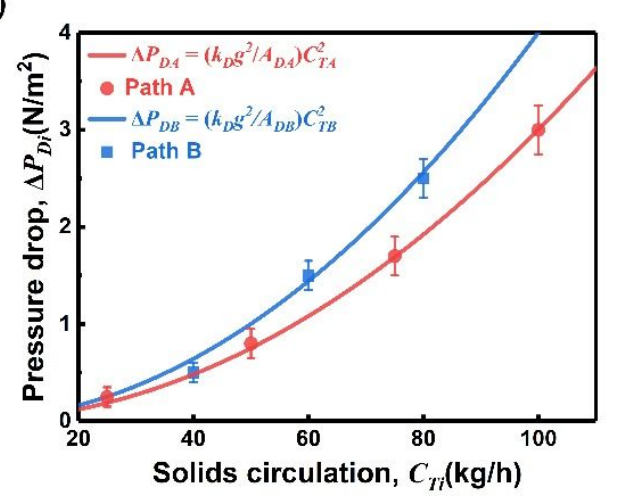

Figure S-3. The relationship between solids circulation rate $\left(C_{T i}\right)$ and (a) transport line pressure drop $\left(\Delta P_{T i}\right)$ and $(b)$ downer pressure drop $\left(\Delta P_{D i}\right)$ in Path $A$ and $B$.

Because the falling solids are in the direction of gravity, rather than average density, kinetic energy dissipation here can be expressed similar with the energy dissipation of continuous fluid phase ${ }^{5}$ : 


$$
\Delta P_{D i}=\frac{k_{D}}{A_{D i}}\left(C_{T i} g\right)^{2} \quad(i=A, B)
$$

where $k_{d i}$ is the geometrical constant in downer. In the present study, $k_{T}=1.15 \times 10^{-6} \mathrm{~h}$ and $k_{D}=1.68 \times 10^{-9} h^{2}$.

In conclusion, the total pressure drop though each path consists of the following three parts: (i) frictional dissipation such as pressure drop across slide valve, which is the 0.5 order of $C_{T i}$; (ii) gravity dissipation such as pressure drop of dense fluidization in hoppers and strippers, which is 1 order of $C_{T i}$; (iii) kinetic dissipation such as pressure drop of dilute solids flow through downer, which is 2 order of $C_{T i}$.

\section{Notation}

\section{Symbols}

$A_{i}=$ area of unit $\left(\mathrm{m}^{2}\right)$

$C_{T}=$ solids circulation rate $(\mathrm{kg} / \mathrm{h})$

$C d_{V i}=$ superficial drag coefficient of slide valve $\left(\mathrm{Nh}^{-1 / 2}\right)$

$d_{p}=$ diameter of particle $(\mathrm{m})$

$H=$ height of solids bed (m)

$k_{c}=$ constant of cooling jacket $\left(\mathrm{kg} / \mathrm{m}^{3}\right)$

$k_{D}=$ geometrical constant of downer $\left(\mathrm{h}^{2}\right)$

$k_{H}=$ geometrical constant of hopper (h)

$k_{S}=$ geometrical constant of stripper $(\mathrm{h})$

$k_{V}=$ geometrical constant of valve $\left(\mathrm{Nh}^{-1 / 2}\right)$

$n=$ expansion parameter

$\mathrm{Re}_{m f}=$ Reynold number with minimal fluidization velocity

$U_{g}=$ superficial gas velocity $(\mathrm{m} / \mathrm{s})$

$U_{m f}=$ minimal fluidization velocity $(\mathrm{m} / \mathrm{s})$

$U_{t}=$ terminal fall velocity $(\mathrm{m} / \mathrm{s})$

\section{Greek symbols}


$\Delta P_{i}=$ pressure drop $\left(\mathrm{kN} / \mathrm{m}^{2}\right)$

$\rho_{\text {ave }}=$ average density of solids bed $\left(\mathrm{kg} / \mathrm{m}^{3}\right)$

$\rho_{g}=$ density of gas stream $\left(\mathrm{kg} / \mathrm{m}^{3}\right)$

$\varepsilon_{s}=$ void fraction of solids bed

$\Phi_{i}=$ valve opening

$\lambda=$ semi-eigenvalue

\section{REFERENCES}

(1) Grace, J. R. Handbook of Multiphase Flow system. Hemisphere Publishing Corp: New York, 1982, pp 213-224.

(2) Richardson, J. F.; Zaki, W. N. Sedimentation and fluidization. Trans. Inst. Chem. Eng. 1954, 32, 35.

(3) Chen, J. Y.; Shi, M. X. A universal model to calculate cyclone pressure drop. Powder Tech. 2007, 171, 184.

(4) Zhang, C. X.; Li, P. L.; Lei, C.; Qian, W. Z.; Wei, F. Experimental study of nonuniform bubble growth in deep fluidized beds. Chem. Eng. Sci. 2018, 176, 515.

(5) Finnemore, E. J.; Franzini, J. B. Fluid Mechanics with Engineering Applications. McGraw-Hill Companies: New York, 2002, pp 73-89. 